\title{
Microstructure and properties of AISi7Mg alloy fabricated by selective laser melting
}

\author{
Shuai Huang, *Shao-qing Guo, Biao Zhou, Guo-hui Zhang, Xue-jun Zhang \\ 3D Printing Research and Engineering Technology Center, Beijing Institute of Aeronautical Materials, Beijing 100095, China
}

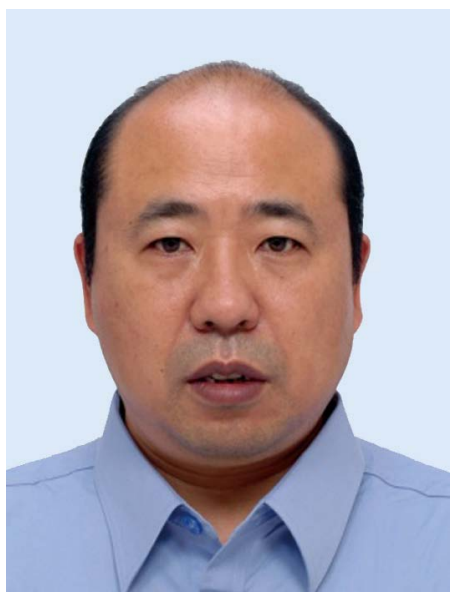

*Shao-qing Guo

Born in 1969, Ph. D., Professor. He obtained his Bachelor and Master degrees at China University of Petroleum (Huadong) in 1992 and 1995, and his Ph. D. at Harbin Institute of Technology in 1999. His research interests mainly focus on welding crack prevention and welding distortion control, numerical simulation of welding thermo-mechanical-microstructure evolution, and additive manufacturing of metals. He has published more than 40 papers in international and domestic journals, and dozens of conference reports. He is now a member of the Computer-Aided Welding Commission of Chinese Welding Society and a member of the China National Standardization Technical Committee of Welding.

E-mail: gsq0046@sina.com

Received: 2021-03-29

Accepted: 2021-05-13
Abstract: The AISi7Mg alloy was fabricated by selective laser melting (SLM), and its microstructure and properties at different building directions after heat treatment were analyzed. Results show that the microstructure of SLM AISi7Mg samples containes three zones: fine grain zone, coarse grain zone, and heat affected zone. The fine-grain regions locate inside the molten pool, and the grains are equiaxed. The coarse-grain regions locate in the overlap of molten pools. After T6 treatment, the microstructure at the molten pool boundary is still the network eutectic $\mathrm{Si}$, but the network structure becomes discrete, and is composed of intermittent, chain-like eutectic Si particles. The yield strength at three directions $\left(x y, 45^{\circ}, z\right.$ direction) of the AISi7Mg alloy samples fabricated by SLM is improved after T6 heat treatment. The fracture mechanism of the samples is a mixed ductile and brittle fracture before heat treatment and ductile fracture after heat treatment.

Key words: selective laser melting; AISi7Mg alloy; microstructure; mechanical property

CLC numbers: TG146.21; Document code: A; Article ID: 1672-6421 2021 04-416-08

\section{Introduction}

It is difficult to prepare complex-shaped parts for aerospace via conventional manufacturing technology ${ }^{[1,2]}$. The additive manufacturing (AM) technology provides a path to solve these problems, and selective laser melting (SLM) technology is one of the most rapidly developed metal AM techniques in recent years ${ }^{[3-5]}$. Metal parts are obtained by laser melting metal powder using a layer by layer method with a rapid cooling rate ${ }^{[6-11]}$.

Aluminum alloys are widely used in various industries due to their high strength to weight ratio ${ }^{[12]}$. However, SLM manufacturing of aluminium alloys begins more recently compared with other alloys. Currently, aluminum alloy SLM forming research was only focused on two alloys: $\mathrm{AlSi} 10 \mathrm{Mg}$ and $\mathrm{Al12} \mathrm{Si}^{[13-15]}$. Because aluminum alloy powder has the characteristics of poor fluidity, low laser absorption, high reflectivity and thermal conductivity, strong oxidation tendency and hot cracking trend, etc., it is difficult to form parts using the SLM method. Expanding the types of aluminum alloys suitable for SLM, and improving forming quality and performance have become the concern of researchers.

Al-Si series aluminum alloys have good welding and casting performance, but their mechanical properties are relatively poor ${ }^{[16]}$. The microstructure of the SLM AlSil0Mg before heat treatment consists of coarse grains at the molten pool boundary and fine grains inside the molten pool. Rosenthal et al. ${ }^{[17]}$ found the nano-scale precipitation of Si particles occurring at $200{ }^{\circ} \mathrm{C}$ were responsible for the strength elevation of AlSi10Mg. After heat treatment, the reticulate Si agglomerated together and formed granular Si phases. After aging at $250{ }^{\circ} \mathrm{C}$ for $2 \mathrm{~h}$, the Si network broken up into separate particles, while, after aging at $300{ }^{\circ} \mathrm{C}$ for $2 \mathrm{~h}$, the Si network broken up into separate coarse precipitates, and a more deeply penetrating corrosion attack was preferentially initiated at the melt pool boundary ${ }^{[18]}$.

AlSi7Mg alloy is a kind of Al-Si hypoeutectic alloy, which has good ductility, high strength and corrosion resistance ${ }^{[19]}$. Compared with AlSi10Mg and Al12Si, AlSi7Mg parts formed by SLM have higher strength and better ductility, and can meet the high reliability requirements 
in the aerospace field ${ }^{[20]}$. The heat treatment can further improve the microstructure of SLM parts, such as recrystallization of grains, defect removal, and uniform microstructure ${ }^{[22]}$. However, the microstructure and properties of SLM AlSi7Mg alloy after heat treatment are not clear.

In this study, AlSi7Mg samples were fabricated by SLM, and the evolution mechanism of microstructure and performance in different directions after T6 heat treatment was analyzed.

\section{Experimental procedure}

Figure 1 shows the morphology and size distribution of AlSi7Mg alloy powder fabricated by gas atomization. It can be seen that the AlSi7Mg powder has high sphericity and smooth surface. The powder particle size is mainly distributed in the range of $5-50 \mu \mathrm{m}$, and the average particle size is $26 \mu \mathrm{m}$.

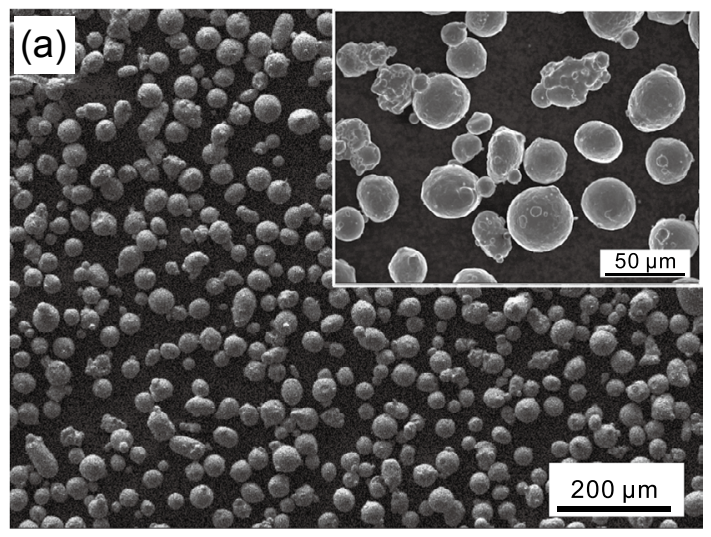

(b)

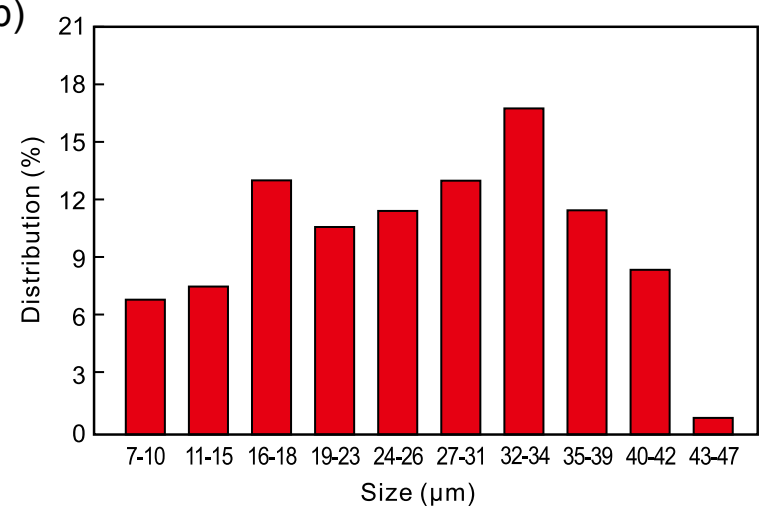

Fig. 1: Morphology of AISi7Mg alloy powder (a) and size distribution (b)

Before using, the powder was put into a drying box to remove the moisture, which could effectively prevent the decomposition of water during SLM, and avoid pores and other defects.

The M2 SLM equipment was used to produce the AlSi7Mg samples. The SLM process consists of three steps: spreading metallic powder, fusing metallic powder and controlling forming thickness. The above three steps were repeated continuously until the required three-dimensional parts were obtained through layer-by-layer forming and superposition. The scanning paths of two adjacent layers are perpendicular to each other. The SLM parameters are shown in Table 1.

Table 1: Parameters of SLM process in this experiment

$\begin{array}{cc}\text { Parameters } & \text { Value } \\ \text { Laser power }(\mathrm{W}) & 280 \\ \text { Scanning speed }\left(\mathrm{mm} \cdot \mathrm{s}^{-1}\right) & 1,250 \\ \text { Layer thickness }(\mu \mathrm{m}) & 60 \\ \text { Hatch spacing }(\mathrm{mm}) & 0.12\end{array}$

The tensile samples in three directions $\left(x y, 45^{\circ}, z\right)$ were prepared according to GB/T228.1-2010, as shown in Fig. 2. The tensile rate was $1 \mathrm{~mm} \cdot \mathrm{min}^{-1}$. The tensile strength, yield strength, and elongation of samples at room temperature were calculated from the stress-strain curves. The average value of 3 measurements was recorded.

T6 heat treatment was carried out for the AlSi7Mg alloy samples (solution treatment at $540{ }^{\circ} \mathrm{C}$ for $6 \mathrm{~h}$, and then ageing at $170{ }^{\circ} \mathrm{C}$ for $8 \mathrm{~h}$ ).

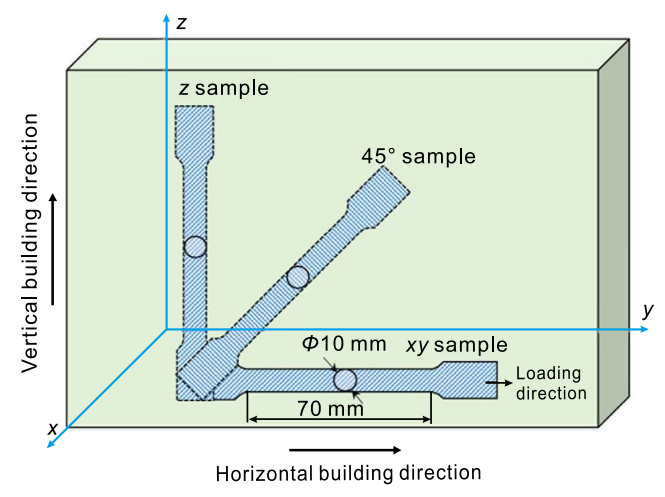

Fig. 2: Geometry of AISi7Mg alloy samples

The samples before and after T6 treatment were polished and etched by Keller's reagent for $15 \mathrm{~s}$. The surface defects and molten pool morphology were observed using an optical microscope. The microstructure and fracture morphology of some tensile samples were observed using a scanning electron microscope (SEM) equipped with an energy dispersive X-ray spectrometer (EDS). The porosity and its distribution after T6 treatment was measured using a micron CT scanner (Vtomex $\mathrm{m} 300$ ) according to GB/T29067-2012, and the resolution was $5.0 \mu \mathrm{m}$. The tube voltage and current were $85 \mathrm{kV}$ and $80 \mu \mathrm{A}$, respectively.

\section{Results and discussion}

\subsection{Microstructure before heat treatment}

Figure 3(a-c) shows the SEM images of AlSi7Mg samples formed by SLM at different directions before heat treatment. The cross-section microstructure of AlSi7Mg consists 

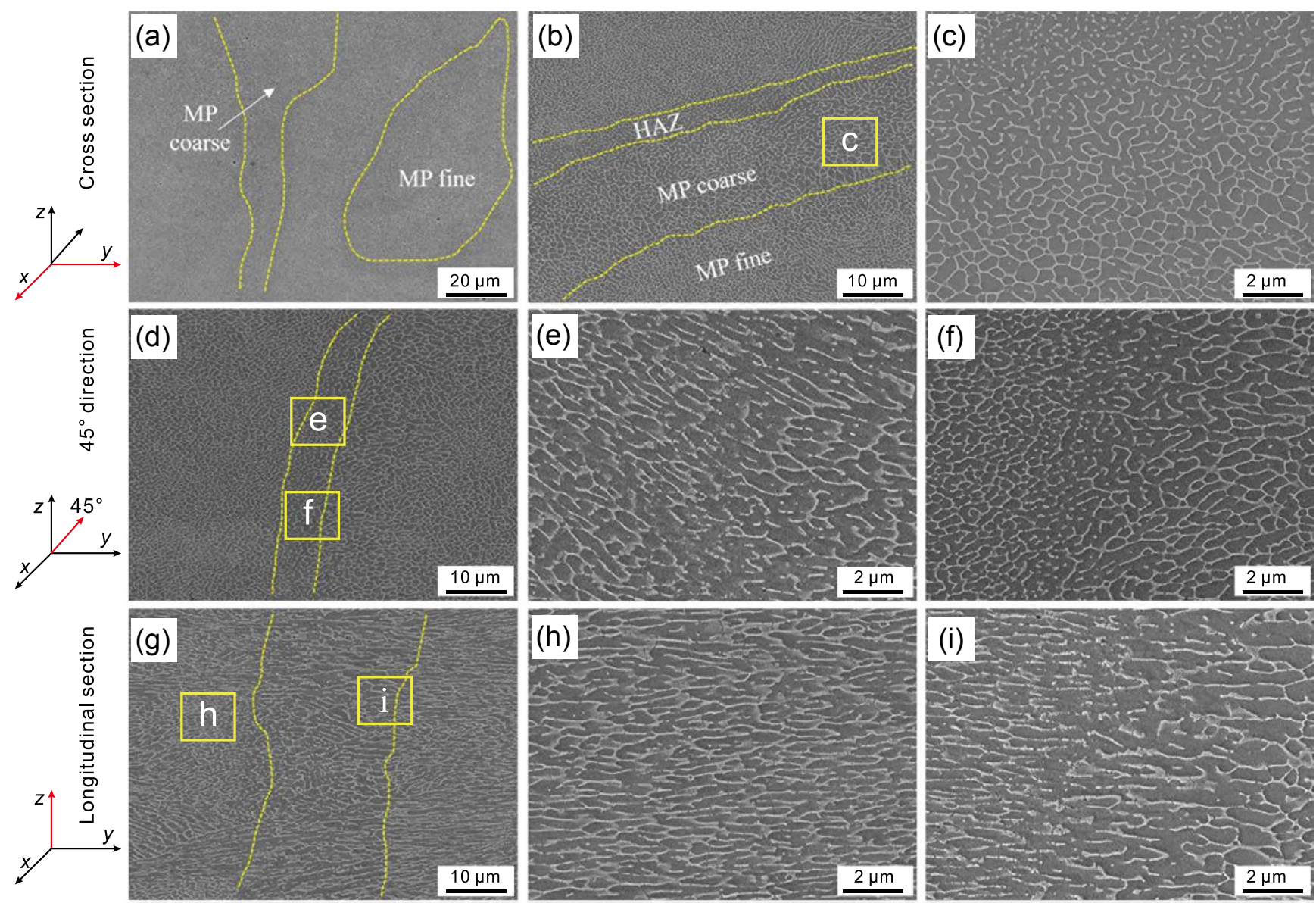

Fig. 3: Microstructures of AISi7Mg alloy sample before heat treatment: (a-c) xy direction sample; (d-f) $45^{\circ}$ direction sample; (g-i) $z$ direction sample, and (c), (e), (f), (h) and (i) are high magnification images of Zones c, e, f, $h$ and $i$, respectively

of columnar fish-scale molten pools, and some pools are overlapped, as shown in Fig. 3(a-c). Some laser tracks, layers, and multilayered structure are found in the molten pool [Fig. 3(d-f)]. Each molten pool could be divided into three regions according to the different grain sizes: the molten pool core (MP fine zone), the overlap of molten pools (MP coarse zone), and the heat-affected zone (HAZ).

A series of thermal processes affect the microstructure of the alloy by SLM, such as laser input energy, heat from the newly melted layer and remelting phenomenon. The high cooling rate in the center of the molten pool makes the crystal grains smaller than those at the edge of the molten pool.

The coarse grain zones locate in the overlap region of the molten pools. The overlap region is partially remelted, and the grains become coarse due to the heat accumulation ${ }^{[23]}$. In addition, the accumulated heat promotes Si to diffuse and precipitate at the molten pool boundary. These grains grow up and finally distribute in the Al matrix in the form of $\mathrm{Si}$ precipitated phases ${ }^{[24]}$. The grain size of HAZ is between that of the fine grain zone and the coarse grain zone.

During the SLM process, the residual heat generated by the newly melted layer perpendicular to the direction of the substrate would cause the solidified layer to remelt. The microstructure of the longitudinal section ( $z$ direction) is shown in Fig. 3(g-i). The dark island region is the $\alpha-\mathrm{Al}$ matrix, and the white network is the eutectic Si phase. The Si phase is found uniformly embedded in the $\alpha$-Al matrix in the center of the molten pool. The remelting proceeds perpendicular to the substrate, causes the crystal grains in the longitudinal section to further grow along the heat flow direction, therefore, the longitudinal-section microstructure shows a slender network structure which is different from the cross-section microstructure.

\subsection{Microstructure after T6 treatment}

The microstructures of AlSi7Mg alloy samples after T6 treatment in $x y, 45^{\circ}$ and $z$ directions are shown in Fig. 4. The dark area is $\alpha-\mathrm{Al}$ matrix, and the white is Si phase. In the xy direction, although the microstructure does not change significantly compared with the sample before heat treatment, the original network morphology gradually disappears, and $\mathrm{Si}$ aggregates along the grain boundary and precipitates in the form of particles.

The microstructures within the molten pool and at the molten pool boundary are shown in Figs. 4(b) and (c). After T6 treatment, the microstructure at the molten pool boundary is still the network eutectic $\mathrm{Si}$, but the network structure becomes noncontinuous, which is composed of intermittent, chain-like eutectic Si particles. The higher the heat treatment temperature, the more serious the merging between grains, and the more 

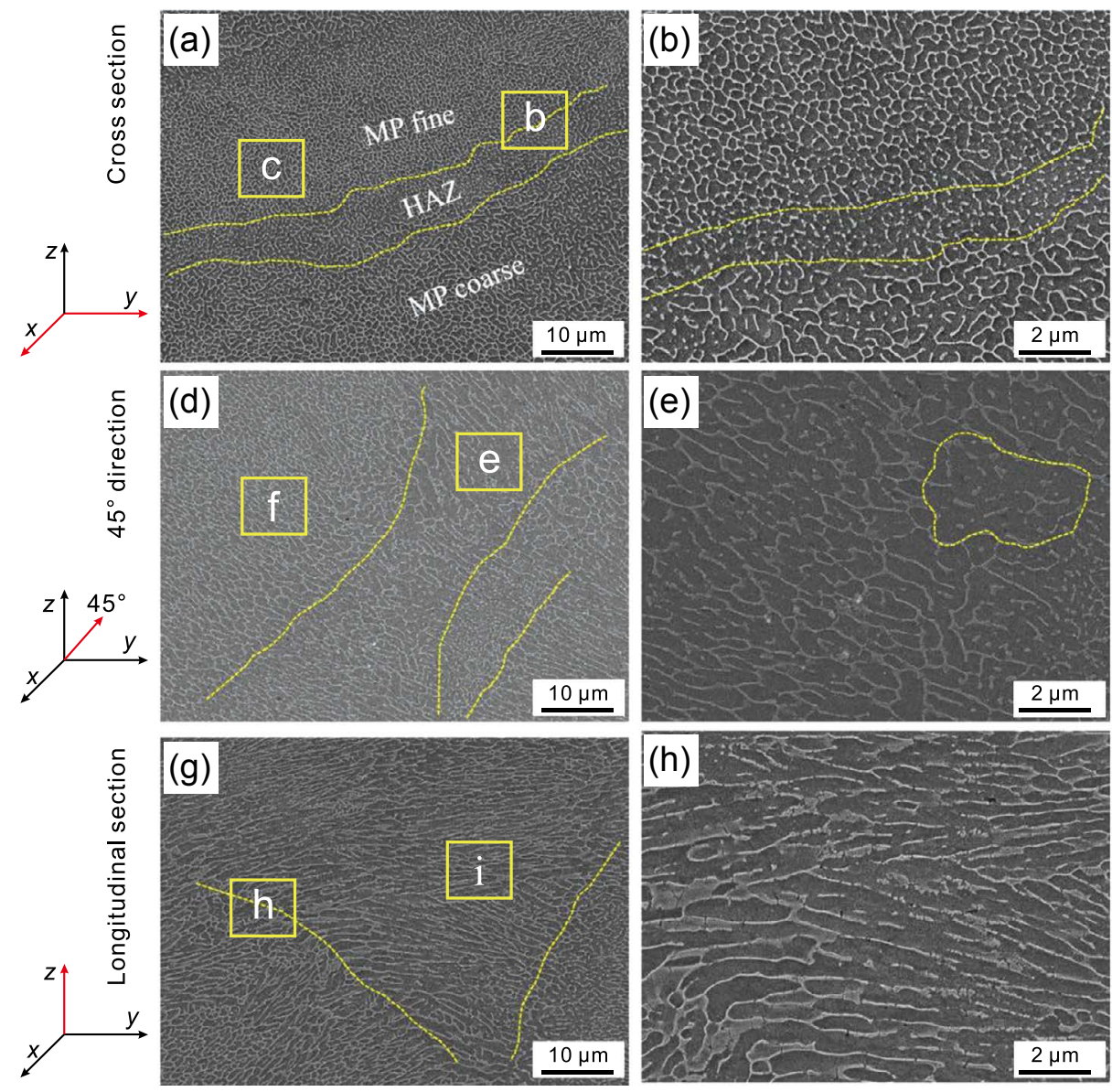
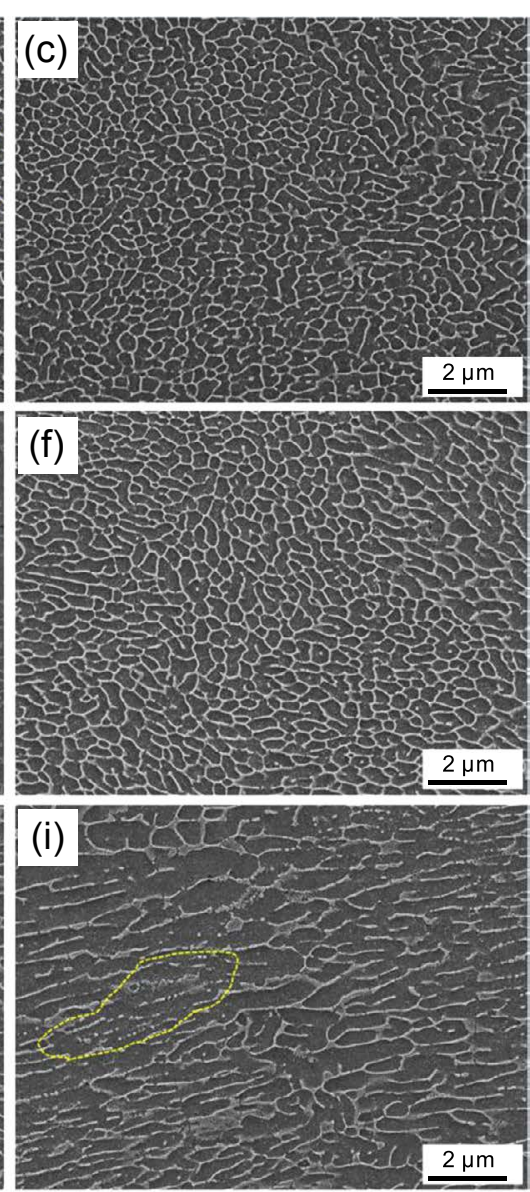

Fig. 4: Microstructures of T6 heat-treated AISi7Mg alloy: (a-c) xy direction sample; (d-f) $45^{\circ}$ direction sample; (g-i) $z$ direction sample; and (b), (c), (e), (f), (h) and (i) are high magnification images of Zones b, c, e, f, h and i, respectively

obvious the coarsening and spheroidization ${ }^{[18]}$. Because solution treatment made $\mathrm{Si}$ supersaturated, artificial aging caused $\mathrm{Si}$ particles to precipitate and aggregate, and the coalescence of small particles and Ostwald maturation increased the size and number of Si particles. The heat treatment process accelerated atomic diffusion. Therefore, with the increase of solid solution temperature, the diffusion of Si accelerates, and the size of the particulate Si precipitated phase increases.

Figure 4(d-f) shows the microstructure of the sample at $45^{\circ}$ direction after $\mathrm{T} 6$ treatment. It can be seen the grains in the MP coarse zone are slightly greater than those at crosssection direction [Figs. 4(b) and 4(e)]. In addition, network morphology begins to disappear [yellow dotted line in Fig. 4(e)]. After T6 heat treatment, the change trend of microstructure in $\mathrm{z}$ directions is not obvious, as shown in Fig. 3(g-i) and Fig. 4(g-i).

Figure 5 shows the $\mathrm{CT}$ images and pore statistics of the samples after heat treatment. The results show that there are 256 pores with a diameter of more than $10 \mu \mathrm{m}$ in the sample. The maximum pore size is $75.84 \mu \mathrm{m}$. The pore size distribution is shown in Fig. 5(d).

\subsection{Mechanical properties}

Figures 6 and 7 show the mechanical properties of the AlSi7Mg samples at different directions before and after heat treatment. It can be seen that the tensile strength, yield strength and elongation of AlSi7Mg samples in the $x y$ direction before heat treatment can reach $436.05 \mathrm{MPa}, 288.25 \mathrm{MPa}$ and $12.68 \%$, and decrease $1.8 \%$, $6.1 \%$ and $33.9 \%$, respectively, in the $\mathrm{z}$ direction. These results indicate that the SLM AlSi7Mg alloy is anisotropic in tensile properties. The grains in the longitudinal direction were larger in size than the cross-section direction [Figs. 3(a) and (g)], which led to fracturing easily for the longitudinal samples.

After T6 treatment, the tensile strength, yield strength and elongation of the samples in $x y$ direction are $430.10 \mathrm{MPa}$, 297.50 MPa and $10.88 \%$, respectively, while those of the $z$ direction are 434.20 MPa, 277.30 MPa and 8.80\%, respectively. The elongation and contraction of area of samples in the $45^{\circ}$ direction slightly decrease after heat treatment. T6 heat treatment did not significantly improve the tensile strength and elongation, but it increased the yield strength in three directions.

\subsection{Fracture morphology}

Figure 8 shows the fracture morphology of SLM AlSi7Mg samples in the $x y$ direction before and after heat treatment. A great number of river-like cleavages and tiny dimples are found in the high magnified images of both samples before and after heat treatment. Therefore, the fracture mechanism of the SLM AlSi7Mg alloy in the $x y$ direction is the ductile and brittle mixed fracture.

In the $45^{\circ}$ samples before heat treatment, as shown in Fig. 9, a 

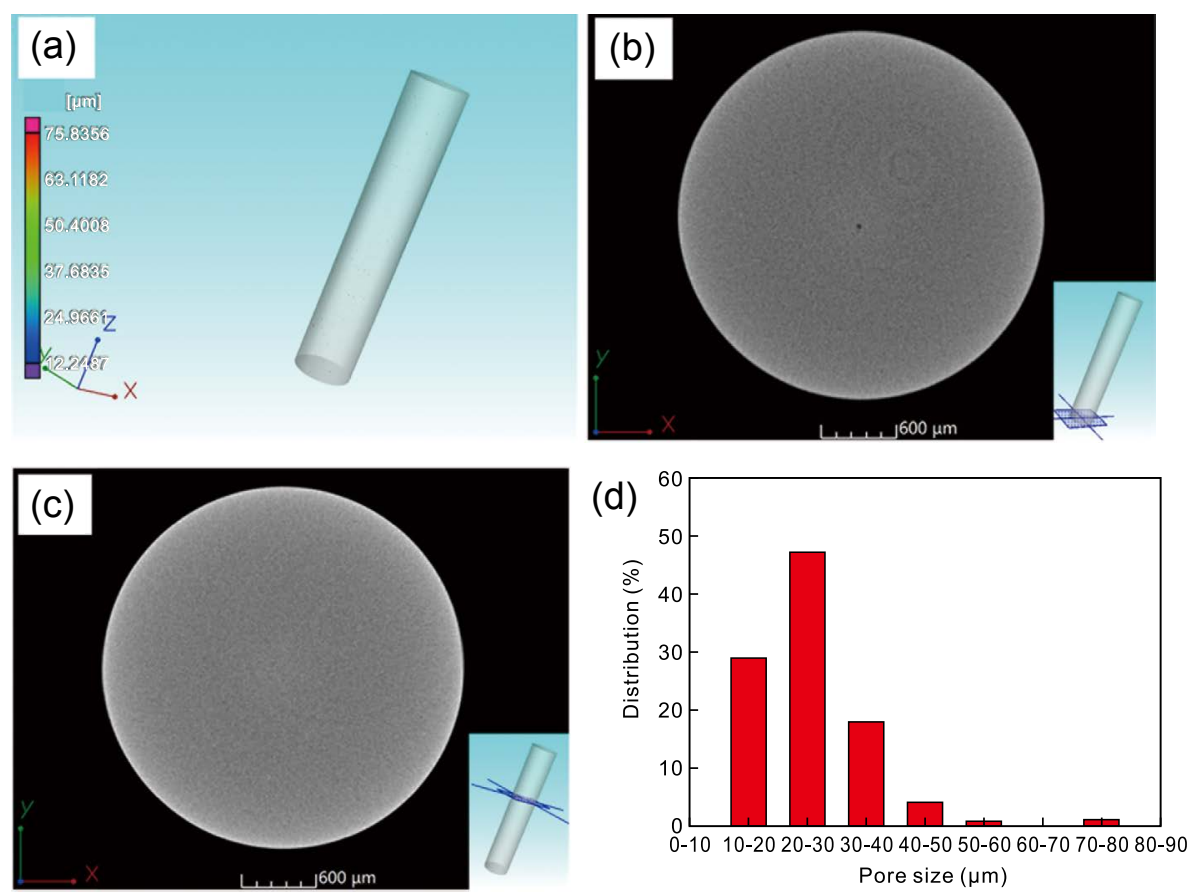

Fig. 5: CT images and pore statistics of samples after T6 treatment: (a) CT samples; (b, c) scanning zones; (d) porosity distribution
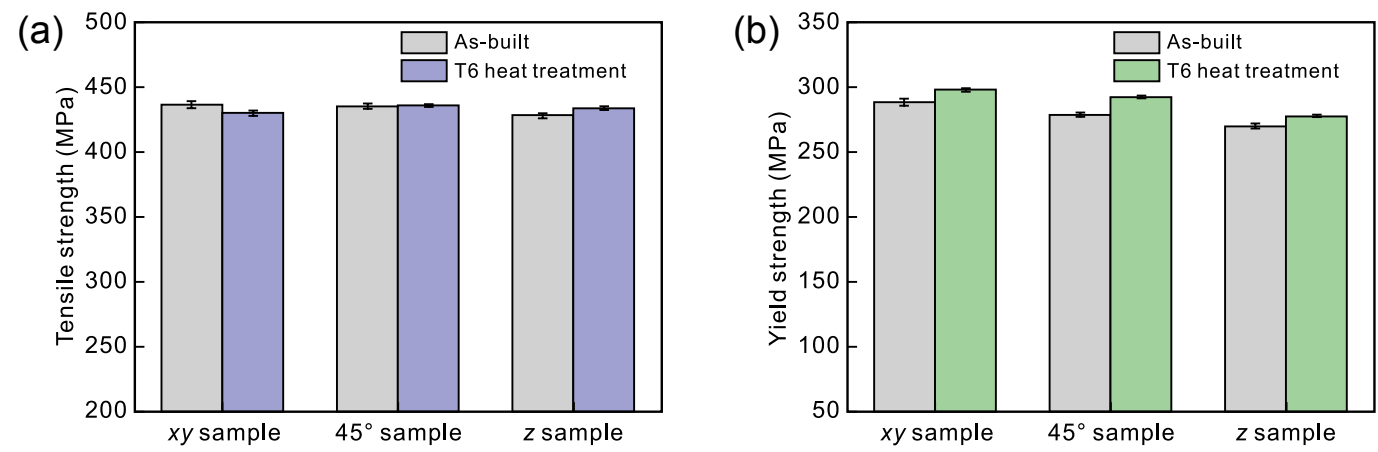

Fig. 6: Comparison of tensile strength (a) and yield strength (b) of samples at different directions before and after T6 heat treatment
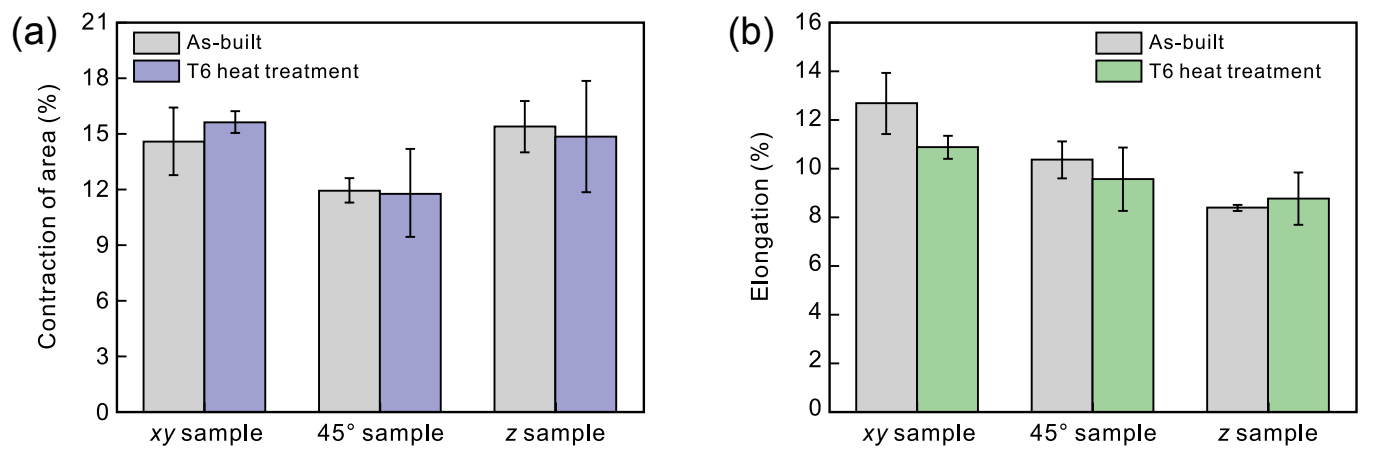

Fig. 7: Comparison of contraction of area (a) and elongation (b) of samples before and after T6 heat treatment

large number of massive bumps can be found uniformly distribute in the fracture surface, indicating a typically intergranular fracture. During the fracture process, cracks first originate in the defect region in the Al matrix, but the network Al-Si eutectic structure hinders the propagation of cracks. As the tensile stress increases, cracks only expand along the Al matrix or network
Al-Si eutectic boundary. After T6 treatment, bumps on the fracture surface are reduced and many dimples form, which characterize the ductile fracture. Therefore, the yield strength in the $45^{\circ}$ direction increased after $\mathrm{T} 6$ treatment.

In the $\mathrm{z}$ direction, as shown in Fig. 10(a), the network eutectic Si hinders the crack propagation. The river-like stepped cleavage 

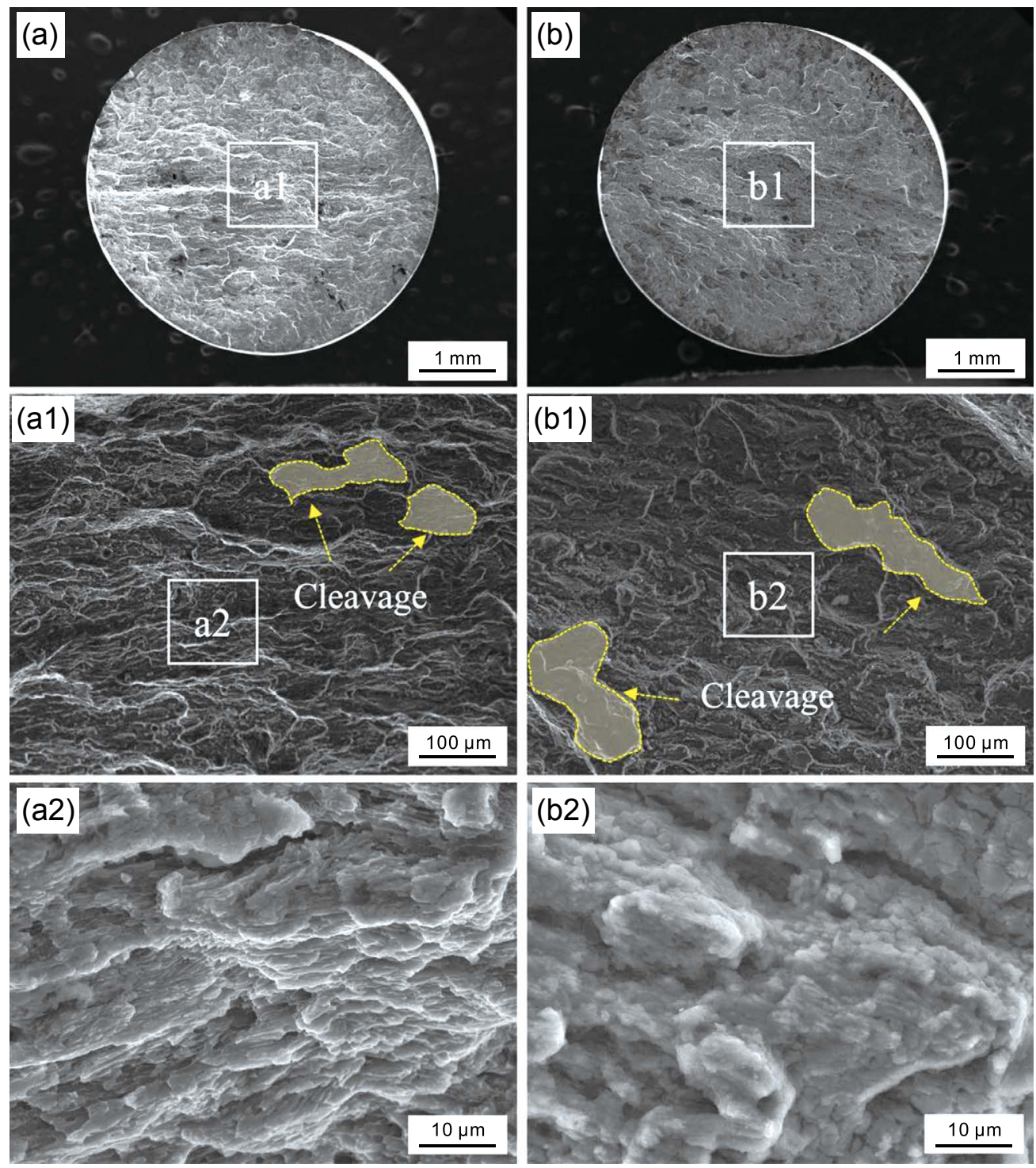

Fig. 8: Fracture morphology of $x y$ samples before (a) and after (b) T6 heat treatment

surface and dimple exist together, therefore, the fracture mechanism of AlSi7Mg alloy before heat treatment is the ductile and brittle mixed fracture.

After T6 treatment, the area of the cleavage surface decreases, and that of the dimples becomes greater, therefore, the fracture mechanism is mainly ductile fracture.

\section{Conclusions}

(1) The microstructure of SLM AlSi7Mg samples containes three zones: fine grain zone, coarse grain zone, and heat affected zone (HAZ). Fine grain zones locate in the molten pool, and grains are equiaxial. The coarse grain zones locate in the overlap of molten pools. The grain size of HAZ is between that of the fine grain zone and the coarse grain zone.

(2) After T6 treatment, the microstructure at the molten pool boundary is still the network eutectic $\mathrm{Si}$, but the network structure becomes noncontinuous, and is composed of intermittent, chain-like eutectic Si particles.

(3) The SLM AlSi7Mg alloy is anisotropic in tensile properties.
T6 heat treatment improves the yield strength in all the three directions. The fracture mechanism of the SLM AlSi7Mg alloy is the ductile and brittle mixed fracture in the $x y$ and $z$ directions, and brittle fracture in the $45^{\circ}$ direction before heat treatment and ductile fracture in the $45^{\circ}$ and $z$ directions and ductile and brittle mixed fracture in the $x y$ direction after heat treatment.

\section{Acknowledgement}

This study was supported by the fund of Beijing Municipal Science and Technology Commission (Z181100003318001).

\section{References}

[1] Jayakrishna K, Kar V R, Sultan M T H. Materials selection for aerospace components. In: M Jawaid, M Thariq (Eds.), Sustainable Composites for Aerospace Applications, Woodhead Publishing Series in Composites Science and Engineering, 2018: 1-18.

[2] Liu Y, Yang Y, Wang D. A study on the residual stress during selective laser melting (SLM) of metallic powder. Int. J Adv. Manuf. Technol., 2016, 87: 647-656. 

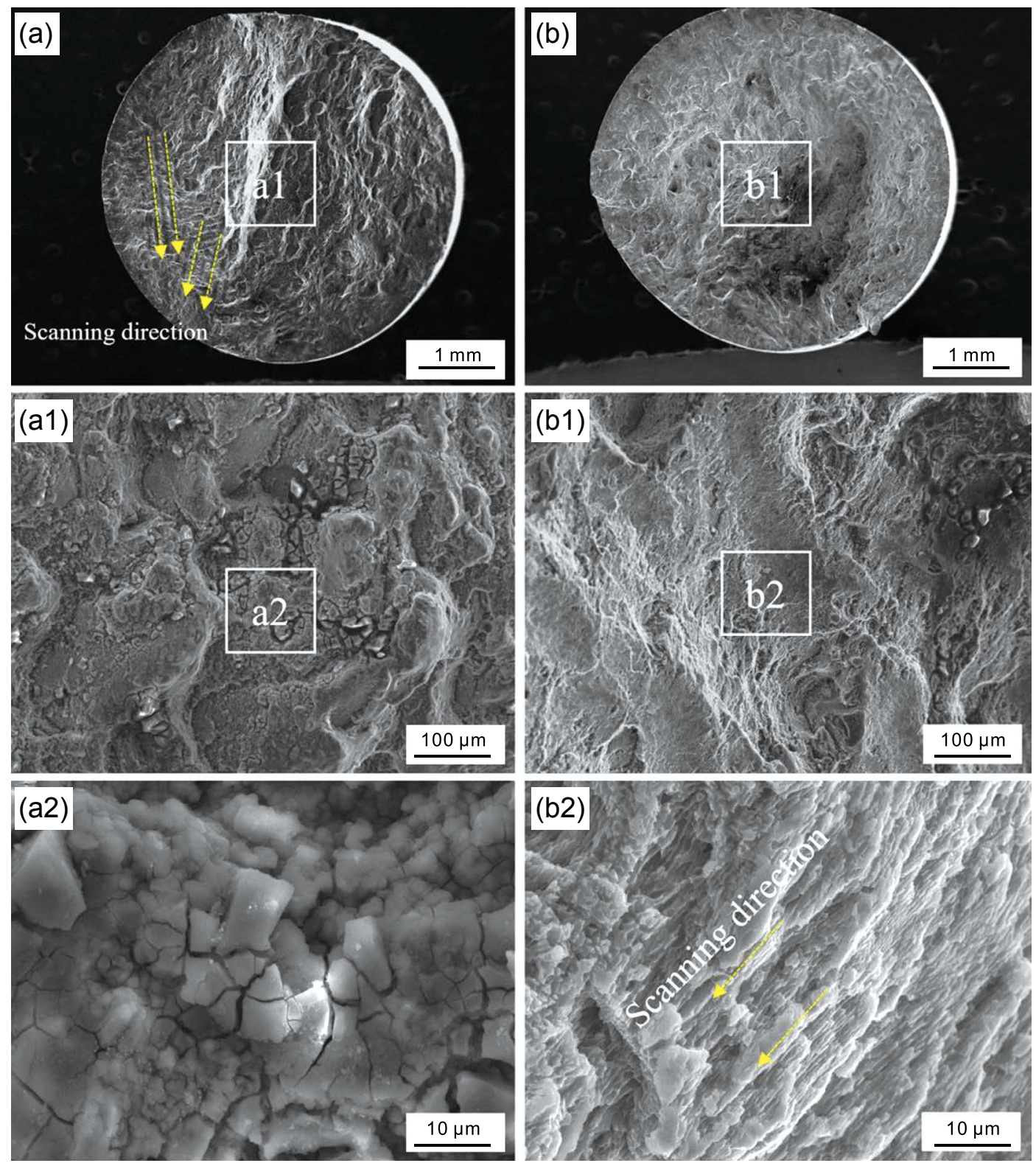

Fig. 9: Fracture morphology of AISi7Mg alloy $45^{\circ}$ samples before (a) and after (b) T6 heat treatment

[3] Louvis E, Fox P, Sutcliffe C J. Selective laser melting of aluminium components. J. Mater. Process. Tech., 2011, 211(2): 275-284.

[4] Yap C Y, Chua C K, Dong Z L, et al. Review of selective laser melting: materials and applications. Appl. Phys. Rev., 2015, 2(4), 041101.

[5] Liu Z, Li X, Wang X, et al. Comparative investigation on grindability of Inconel 718 made by selective laser melting (SLM) and casting. Int. J Adv. Manuf. Technol., 2019, 100: 3155-3166.

[6] Aboulkhair N T, Everitt N M, Maskery I, et al. Selective laser melting of aluminum alloys. MRS Bulletin, 2017, 42: 311-319.

[7] Chlebus E, Kuźnicka B, Kurzynowski T, et al. Microstructure and mechanical behaviour of Ti-6Al-7Nb alloy produced by selective laser melting. Mater. Charact., 2011, 62(5): 488-495.

[8] Yang L, Ferrucci M, Mertens R, et al. An investigation into the effect of gradients on the manufacturing fidelity of triply periodic minimal surface structures with graded density fabricated by selective laser melting. J. Mater. Process. Tech., 2020, 275: 116367.

[9] Abe F, Osakada K, Shiomi M, et al. The manufacturing of hard tools from metallic powders by selective laser melting. J. Mater. Process. Tech., 2001, 111(1-3): 210-213.
[10] Vrancken B, Thijs L, Kruth J P, et al. Heat treatment of Ti6Al4V produced by selective laser melting: Microstructure and mechanical properties. J. Alloy Compd., 2012, 541: 177-185.

[11] Buchbinder D, Schleifenbaum H, Heidrich S, et al. High power selective laser melting (HP SLM) of aluminum parts. Physics Procedia, 2011, 12: 271-278.

[12] Kenevisi M S, Lin F. Selective electron beam melting of high strength Al2024 alloy: Microstructural characterization and mechanical properties. J. Alloy Compd., 2020, 843: 155866.

[13] Li X W, Shi S, Han S, et al. Microstructure, solidification behavior and mechanical properties of Al-Si-Mg-Ti/TiC fabricated by selective laser melting. Addit. Manuf., 2020, 34: 101326.

[14] Marola S, Manfredi D, Fiore G, et al. A comparison of selective laser melting with bulk rapid solidification of AlSi10Mg alloy. J. Alloy Compd., 2018, 742: 271-279.

[15] Dong Z C, Liu Y B, Zhang Q, et al. Microstructural heterogeneity of AlSi10Mg alloy lattice structures fabricated by selective laser melting: Phenomena and mechanism. J. Alloy Compd., 2020, 833: 155071.

[16] Lewandowski J J, Seifi M. Metal additive manufacturing: a review of mechanical properties. Annu. Rev. Mater. Res., 2016, 46: 151-186. 

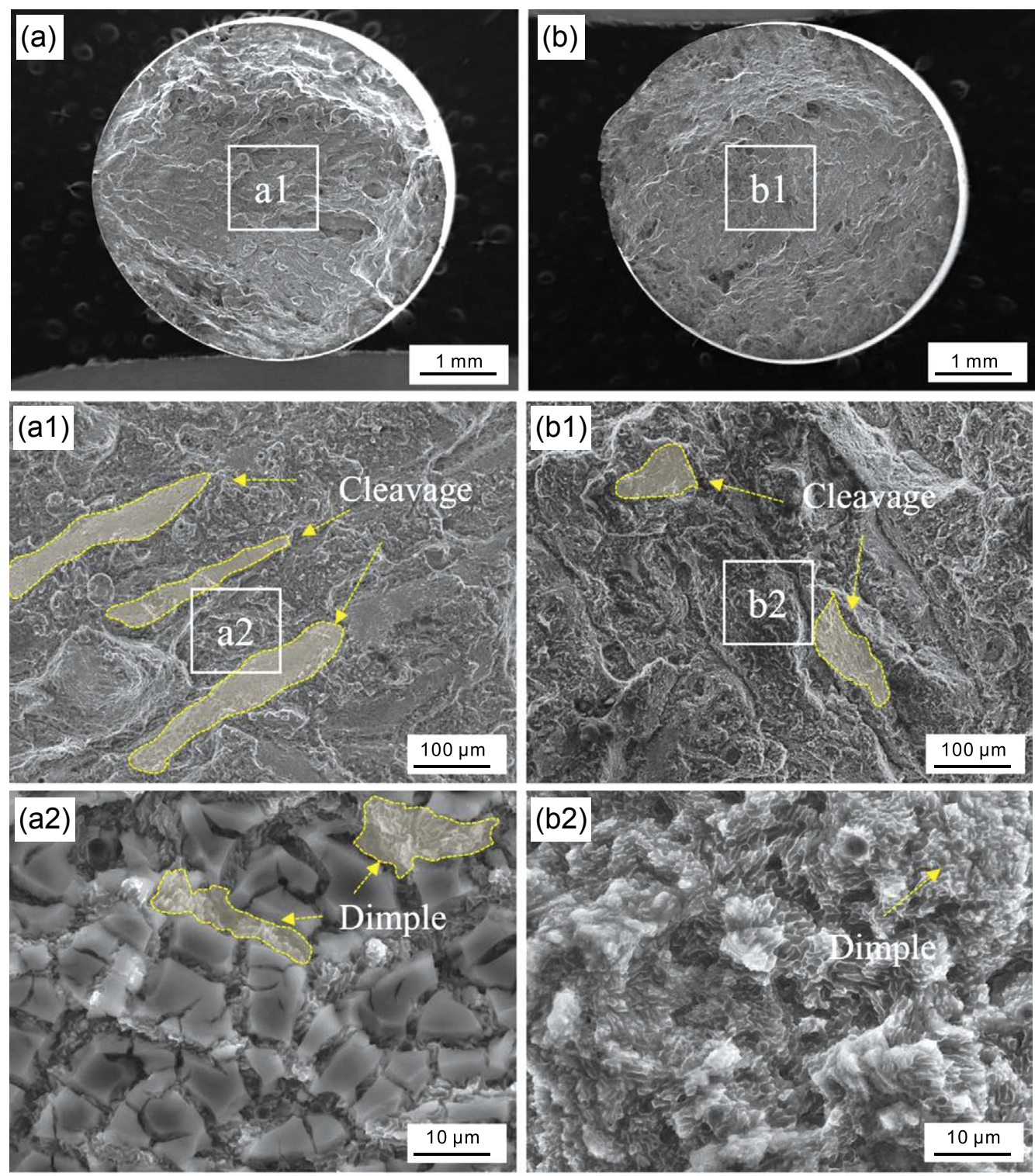

Fig. 10: Fracture morphology of AISi7Mg z samples before (a) and after (b) T6 heat treatment

[17] Rosenthal I, Shneck R, Stern A. Heat treatment effect on the mechanical properties and fracture mechanism in AISi10Mg fabricated by additive manufacturing selective laser melting process. Mater. Sci. Eng. A, 2018, 729: 310-322.

[18] Rubben T, Revilla R I, Graeve I D. Influence of heat treatments on the corrosion mechanism of additive manufactured AlSi10Mg. Corros. Sci., 2019, 147: 406-415.

[19] Mao W, Li Y, Zhao A, et al. The formation mechanism of nondendritic primary $\alpha-A l$ phase in semi-solid AlSi7Mg Alloy. Sci. Technol. Adv. Mat., 2001, 2(1): 97-99.

[20] Boniotti L, Beretta S, Patriarca L, et al. Experimental and numerical investigation on compressive fatigue strength of lattice structures of AISi7Mg manufactured by SLM. Int. J Fatigue, 2019, 128: 105181.
[21] Dong S S, Zhang X X, Ma F, et al. Research on deposited tracks and microstructures of AISi $10 \mathrm{Mg}$ alloy produced by selective laser melting. Appl. Phys. A, 2020, 126(8): 643.

[22] Takata N, Kodaira H, Sekizawa K, et al. Change in microstructure of selectively laser melted AISi10Mg alloy with heat treatments. Mater. Sci. Eng. A, 2017, 704: 218-228.

[23] Prashanth K G, Scudino S, Klauss H J, et al. Microstructure and mechanical properties of Al-12Si produced by selective laser melting: effect of heat treatment. Mater. Sci. Eng. A, 2014, 590: 153-160. 